\title{
Monitoring Ruangan Berbasis Internet of Things Menggunakan Thingsboard dan Blynk
}

\author{
Yudi Eko Windarto ${ }^{1}$, Bryan Monang Wiener Samosir², Muhammad Richie Assariy ${ }^{3}$ \\ 123 Universitas Diponegoro Semarang \\ yudi@live.undip.ac.id, bryanm@student.ce.undip.ac.id, \\ richieassariy@students.undip.ac.id
}

\begin{abstract}
Technology designed to facilitate humans in a variety of work. A very popular technology today is the Internet of Things. The application of Internet of Things technology is widely used in various fields at present. One was used to monitor the room. The methodology used in this study is a Hardware Development Life Cycle (HDLC). The results of this research that the device can transmit ambient conditions via the Internet of Things with protocol Message Queuing Telemetry Transport (MQTT). In this study, Raspberry Pi serves as an intermediary between the media data is read by the sensor is then stored on the application Thingsboard. In addition the application Blynk used as a medium for monitoring the device remotely.
\end{abstract}

Keyword : Internet of Things, MQTT, Thingsboard, Blynk

\begin{abstract}
Abstrak
Teknologi dibuat untuk mempermudah manusia dalam melakukan berbagai pekerjaan. Teknologi yang sangat populer pada zaman sekarang yaitu Internet of Things. Penerapan teknologi Internet of Things banyak digunakan dalam berbagai bidang pada saat ini. Salah satunya dimanfaatkan untuk melakukan monitoring ruangan. Metodologi yang digunakan dalam penelitian ini adalah metode Hardware Development Life Cycle (HDLC). Hasil penelitian ini yaitu perangkat dapat mengirimkan kondisi ruangan melalui Internet of Things dengan protocol Message Queuing Telemetry Transport (MQTT). Pada penelitian ini, Raspberry Pi berfungsi sebagai media perantara antara data yang dibaca oleh sensor kemudian disimpan pada aplikasi Thingsboard. Selain itu aplikasi Blynk digunakan sebagai media untuk melakukan monitoring perangkat dari jarak jauh.
\end{abstract}

Kata Kunci : Internet of Things, MQTT, Thingsboard, Blynk

http://journal.walisongo.ac.id/index.php/jit/index WJIT : Walisongo Journal of Information Technology

WJIT : Walisongo Journal of Information Technology - Vol.2 No. 2 (2020) 


\section{PENDAHULUAN}

Teknologi diciptakan untuk membantu aktivitas dan pekerjaan manusia (Fan et al., 2017). Salah satu dari teknologi tersebut yaitu Internet of Things (Vadillo, Martín-Ruiz, Pau, Conde, \& Valero, 2017). Sehingga peran dari teknologi Internet of Things yang sangat berguna untuk menghubungkan antara dunia nyata dengan dunia digital (Park, Cho, Han, \& Kwon, 2017).

Teknologi Internet of Things banyak digunakan dalam berbagai bidang (Zhu, Xu, \& Gao, 2020). Pengembangan Internet of Things dalam bidang industri telah berfokus pada perangkat sensor yang dapat dipakai dan di dalam ruang kerja (Vaidya \& Vishwakarma, 2018). Perangkat yang selalu dipakai biasanya dipasang di berbagai ruangan untuk mendapatkan data spesifik (Xu, He, Sun, He, \& Xu, 2020). Namun, terdapat beberapa perangkat yang dipasang tidak cocok untuk di lingkungan yang lembab (Mao, Li, Zhang, \& Liang, 2017). Hal tersebut karena pada ruangan tersebut memiliki kadar uap air yang terlalu tinggi (Media's, ., \& Rif'an, 2019). Oleh karena itu, sensor harus diletakkan pada tempat yang aman (De Paolis, De Luca, \& Paiano, 2018).
Sensor IoT menyediakan data dengan biaya rendah, terukur, efisien, berdaya rendah, dan terintegrasi melalui semua sub-jaringan (Patel, Patel, Scholar, \& Iot, 2018) . Sensor yang terpasang biasanya terhubung dengan mikrokontroler (Wagyana, Zulhelman, \& Rahmat, 2019) . Salah satu perangkat mikrokontroler yang banyak digunakan saat ini adalah Raspberry Pi (Wai Zhao, Jegatheesan, \& Chee Loon, 2015). Raspberry Pi memiliki keunggulan, yaitu sangat mudah dipelajari bagi pemula (Koo, Lee, Sebastiani, \& Kim, 2016)

Pada penelitian ini bertujuan untuk melakukan monitoring ruangan secara langsung dari jarak jauh. Raspberry Pi berfungsi sebagai media perantara antara data yang dibaca oleh sensor kemudian disimpan pada aplikasi Thingsboard. Selain itu aplikasi Blynk digunakan sebagai media untuk melakukan monitoring perangkat dari jarak jauh.

\section{METODE}

Metode yang digunakan di dalam penelitian ini adalah Hardware Development Life Cycle. Metode ini dipilih karena pengembangan ini cocok untuk proyek dengan skala kecil. Metode HDLC ditunjukkan pada Gambar 1. 


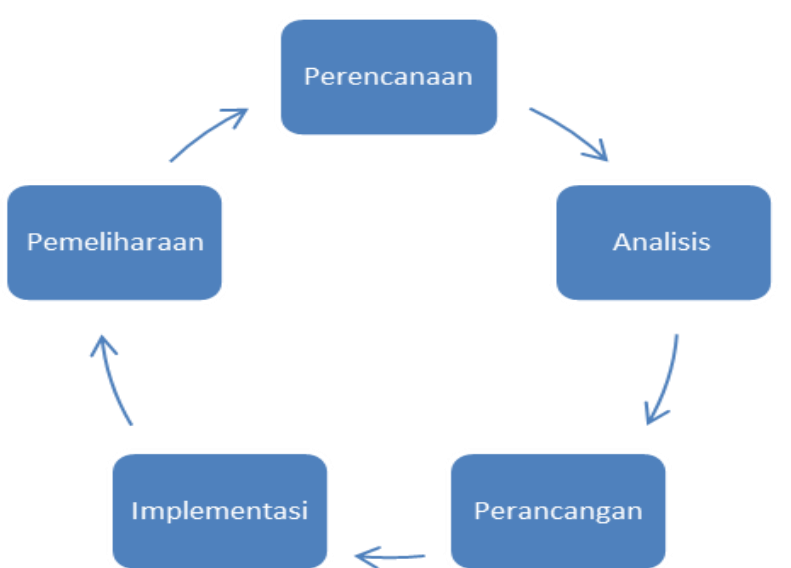

\subsection{Perencanaan}

Pada tahapan ini dilakukan perencanaan terhadap perangkat keras mikrokontroler sebagai perangkat yang akan membaca hasil data dari sensor. Data dari sensor mendeteksi kondisi ruangan serta mengirim data tersebut ke server Thingsboard dan Blynk.

2.2 Analisis Kebutuhan

Pada tahapan ini diperoleh klasifikasi masalah, peluang, dan solusi yang mungkin diterapkan untuk pengerjaan perangkat. Dalam analisis juga ditentukan kebutuhan dari sistem dan juga batasan sistem. Dari analisis kebutuhan dapat disimpulkan permasalahannya adalah tidak adanya suatu fasilitas atau

Gambar 1

Metode HDLC

perangkat yang tersedia untuk memonitor kondisi suatu ruangan dari jarak jauh.

\subsection{Perancangan Perangkat}

Tahapan ini merupakan tahap penerjemahan dari kebutuhan fungsional dan data yang telah dianalisis ke dalam bentuk yang mudah dimengerti. Pada tahap perancangan ini akan dibuat bagaimana bagian perangkat dapat terhubung. Perancangan perangkat terdiri dari perancangan perangkat keras dan perancangan perangkat lunak. Pada perancangan perangkat keras ditunjukkan pada Gambar 2 . 


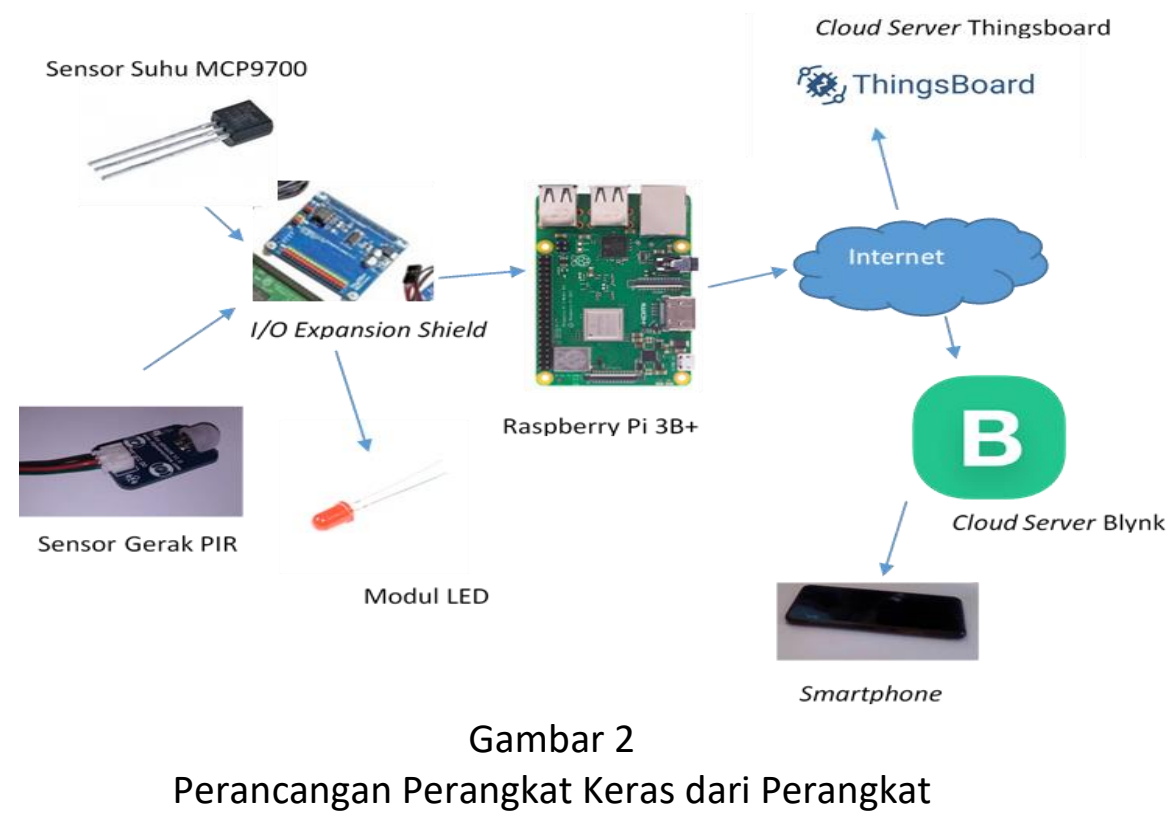

2.4 Implementasi

Pada tahapan ini dilakukan implementasi dari perancangan system yang telah dibuat. Perangkat keras mikrokontroler sebagai perangkat yang akan membaca hasil data dari sensor.

2.5 Pemeliharaan

Merupakan tahap perbaikan terhadap error yang muncul pada perangkat maupun permintaan perubahan. Perangkat juga butuh untuk disesuaikan jika ada penambahan beban perangkat atau jika dibutuhkan penambahan fungsi perangkat.

Pada pengembangan perangkat dan layanan Internet of Things yang digunakan masih sangat terbuka karena mudahnya skalabilitas perangkat. Menggunakan server lokal Internet of Things untuk memudahkan pengembangan jaringan dan jumlah perangkat terhubung.

\section{KERANGKA TEORI}

\subsection{Raspberry Pi 3B+}

Raspberry Pi 3 Model B + adalah produk terbaru dari jajaran produk Raspberry $\mathrm{Pi} 3$, memperlihatkan prosesor quad core 64-bit yang bekerja pada $1.4 \mathrm{GHz}$, dual-band $2.4 \mathrm{GHz}$ dan $5 \mathrm{GHz}$ LAN nirkabel, Bluetooth 4.2 / BLE, Ethernet lebih cepat, dan kemampuan PoE melalui HAT PoE terpisah (Kamalakannan \& Devadharshini, 2019) .

3.2 I/O Expansion Shield

I/O Expansion Shield merupakan modul I/O yang disertakan dalam Raspberry Starter Kit. Raspberry Pi Starter Kit merupakan kit pembelajaran readyto-use yang terdiri dari Raspberry Pi dan beberapa modul pendukung. 
Dengan kit ini dapat memudahkan mempelajari fungsi GPIO, cara mengakses GPIO, cara mengambil data sensor melalui GPIO (Zlatanov, 2016) .

\subsection{MPC9700}

Sensor suhu dengan Linear Active Thermistor IC. Sensor MPC9700 menyediakan solusi biaya murah untuk pengukuran perubahan suhu. MPC9700 juga dapat dipasang terpisah dari mikrokontroler sehingga memberi keleluasaan untuk perancangan PCB (Microchip Technology Incorporate, 2007) .

\subsection{Sensor PIR}

Sensor PIR (Passive Infrared) dapat mendeteksi gerakan pada jangkauan jarak 2 sampai 5 meter. Sensor PIR merupakan piranti Pyroelectric yang mendeteksi gerak dengan mengukur perubahan tingkat radiasi inframerah yang dipancarkan obyek-obyek di sekitarnya (Syahidulhaq, Hafiddudin, \& Aulia, 2017) .

\subsection{Python}

Python adalah bahasa pemrograman yang berorientasi obyek dinamis, dapat digunakan untuk pengembangan perangkat lunak. Python memiliki pustakapustaka standar yang dapat diperluas serta dapat dipelajari hanya dalam beberapa hari (Perkasa, Widyantara, \& Susanto, 2014) .

\subsection{Thonny IDE}

Thonny merupakan IDE Python yang dapat membuat visualisasi program untuk membantu pemula. Thonny IDE mendukung penelitian karena Thonny IDE digunakan untuk menganalisa proses pemrograman. Thonny IDE dapat digunakan gratis dan bisa dilakukan pengembangan (Annamaa, 2015) .

\subsection{Message Queuing Telemetry Transport (MQTT) \\ Message Queuing Telemetry} Transport (MQTT) merupakan sebuah protokol yang diterapkan pada Internet of Things. Protokol ini sangat mendukung untuk jaringan Wide Area Network, karena Wide Area Network mencakup area yang luas. Protokol Message Queuing Telemetry Transport (MQTT) mempunyai kelebihan yaitu dapat bekerja dengan energi dan media penyimpanan yang minimum (Kashyap, Sharma, \& Gupta, 2018) .

3.8 Thingsboard

Thingsboard merupakan sebuah platform Internet of Things (IoT) yang bersifat open source. Thingsboard merupakan web server yang dapat digunakan sebagai platform manajemen device, pengumpulan data, dan visualisasi data berbasis website. Data yang sudah dibaca oleh sensor kemudian dikirimkan ke web server thingsboard (De Paolis et al., 2018).

3.9 Blynk

Blynk merupakan aplikasi yang berbasis IOS atau Android untuk mengontrol mikrokontroler melalui internet (Media's et al., 2019). Aplikasi Blynk dapat juga digunakan membantu tugas admin dalam memonitoring sesuatu dengan praktis. Blynk dirancang untuk Internet of Things (Pareek, Padaki, Iyer, \& Priya, 2017). 
Dapat mengontrol perangkat keras dari jarak jauh, dapat menampilkan data sensor, dapat menyimpan hasil yang ditampilkan oleh data, dan melakukan banyak hal lainnya.

\section{PEMBAHASAN}

\begin{tabular}{lrr}
\multicolumn{2}{c}{ Peneliti } & \multicolumn{2}{c}{ memanfaatkan } \\
aplikasi & Thingsboard dalam \\
melakukan & manajemen pada \\
perangkat & keras. & Selain itu, \\
Thingsboard & juga menyediakan \\
layanan basis data dalam mendukung
\end{tabular}

integrasi antara sensor yang digunakan. Protokol yang digunakan untuk komunikasi antar perangkat adalah protokol Message Queuing Telemetry Transport (MQTT). Node server pada ThingsBoard bertindak sebagai Broker MQTT yang mendukung level QoS 0 (paling banyak sekali) dan 1 (setidaknya sekali) dan satu set topik yang telah ditentukan. Penentuan aturan node pada Thingsboard ditunjukkan Gambar 3.

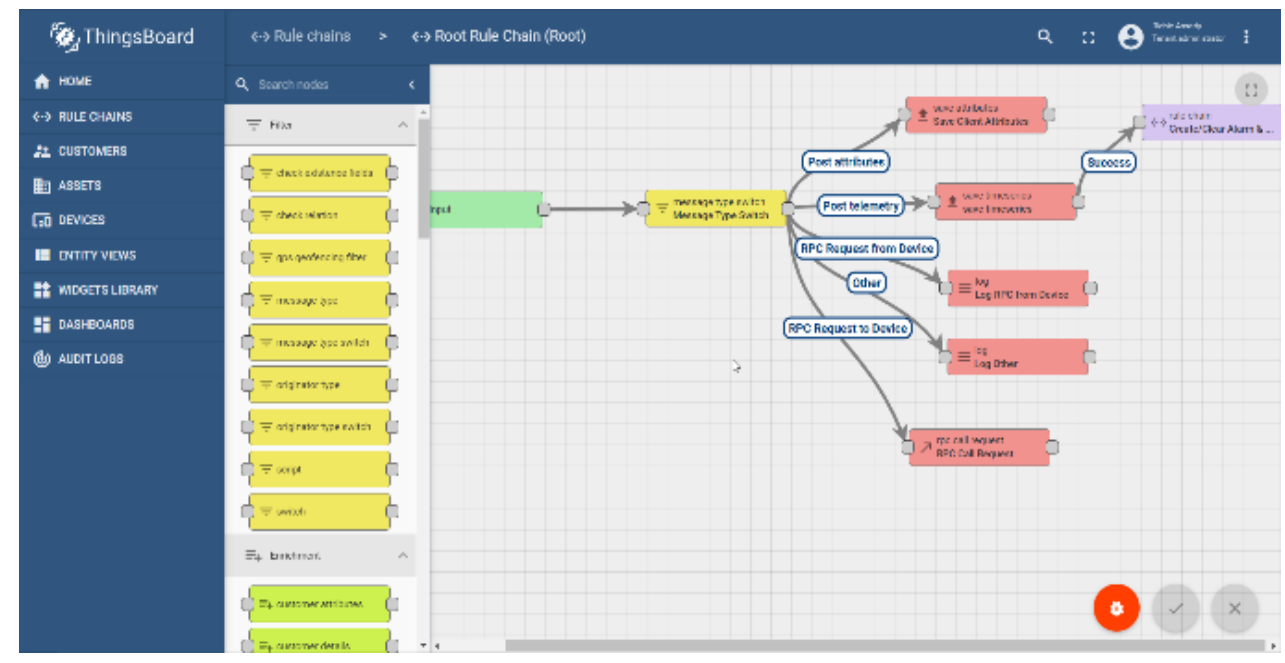

\section{Gambar 3}

Aturan Node pada Thingsboard

Selanjutnya peneliti dapat tidak boleh melebihi dari 40 derajat melakukan pengaturan terhadap isi node dari email yang akan dikirim ke alamat email tertentu berupa peringatan bahwa suhu yang dideteksi berada diluar ambang batas celcius. Peneliti juga dapat melakukan pengaturan terhadap alamat email yang akan menerima pesan dari aplikasi thingsboard ditunjukkan oleh normal. Batas suhu yang digunakan Gambar 4 . 


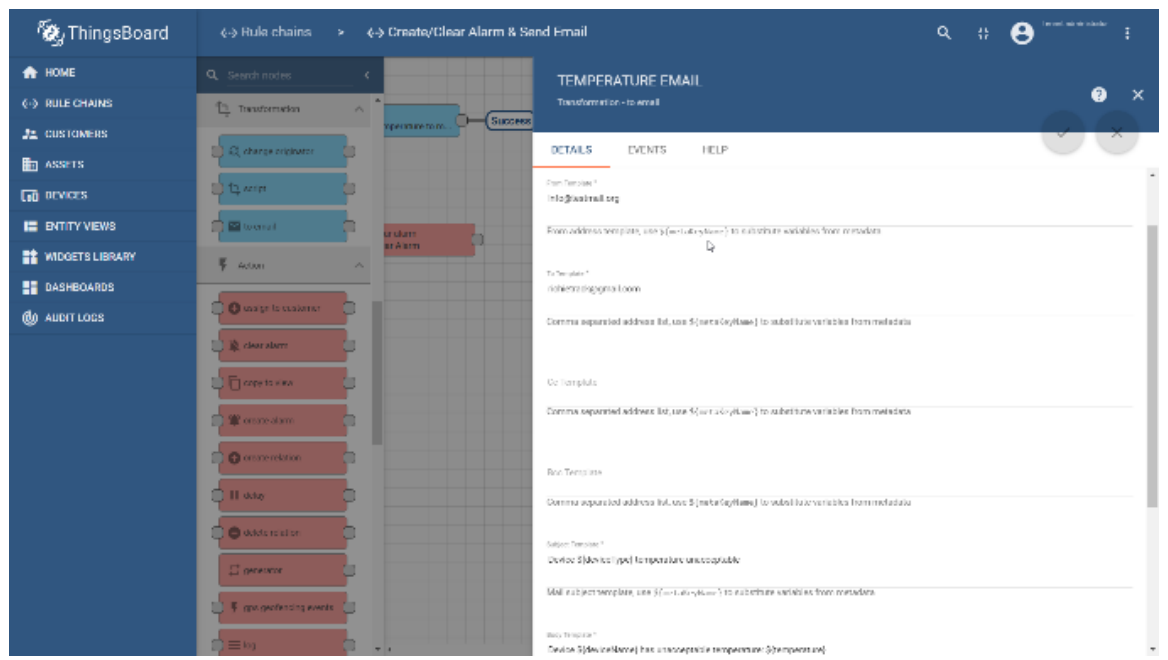

Gambar 4

Pengaturan Pesan dari Node Menuju Email Penerima

Pengujian terhadap sensor suhu dilakukan dengan membandingkan hasil dari sensor suhu MCP9700 dengan pengukuran Indoor Thermo-Higrometer HTC-1.
Pengujian dilakukan selama satu jam secara berkala pada sebuah ruangan. Hasil pengujian yang dilakukan oleh peneliti ditunjukkan pada Error! Reference source not found. .

Tabel 1

Perbandingan Hasil Pengukuran Suhu Ruangan

\begin{tabular}{|c|c|c|c|}
\hline Jam & МСР9700 & HTC-1 & Selisih \\
\hline $12: 20: 00$ & 26.07 & 26.2 & 0.13 \\
\hline $12: 30: 00$ & 26.19 & 26.2 & 0.01 \\
\hline $12: 40: 00$ & 26.92 & 26.8 & 0.12 \\
\hline $12: 50: 00$ & 26.92 & 26.6 & 0.32 \\
\hline 13:00:00 & 27.05 & 26.1 & 0.95 \\
\hline 13:10:00 & 27.05 & 26.8 & 0.25 \\
\hline 13:20:00 & 27.17 & 26.8 & 0.37 \\
\hline \multicolumn{3}{|c|}{ Rata-rata selisih } & 0.31 \\
\hline
\end{tabular}

Hasil pengujian perbedaan suhu antara Sensor MCP9700 dengan Thermo-Higrometer HTC-1 adalah 0.31 . Hasil pengukuran menujukkan bahwa suhu yang diukur perangkat tidak memiliki perbedaan besar dengan hasil pengukuran suhu perangkat lain. Hal ini merupakan hal penting terutama terkait dengan pengaturan alarm pada perangkat. Selain itu, terdapat sensor PIR yang digunakan pada penelitian untuk mendeteksi gerakan yang ada dalam ruangan. Thingsboard sebagai 
layanan Internet of Things memiliki fitur dashboard yang berfungsi untuk menampilkan data yang masuk dari perangkat yang digunakan oleh peneliti. Selain itu, dashboard juga dapat menampilkan data dalam bentuk widget yang disediakan oleh Thingsboard. Hasil tampilan dashboard Thingsboard terlihat pada Gambar 5.

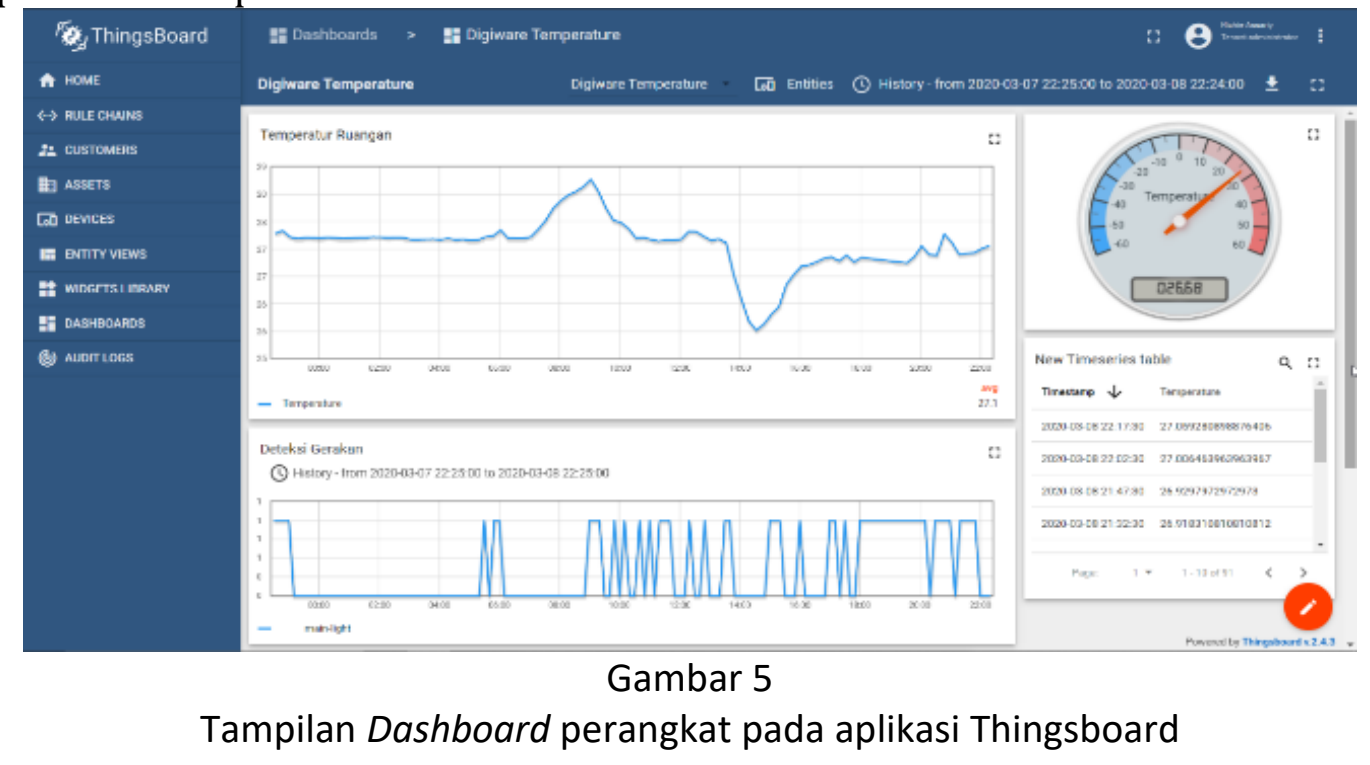

Peneliti dapat melakukan suhu serta pergerakan dapat monitoring terhadap suhu dan diperoleh melalui canvas Blynk pergerakan menggunakan aplikasi terlihat pada Error! Reference Blynk. Aplikasi Blynk dapat diakses source not found. melalui perangkat bergerak berbasis Android. Hasil monitoring terhadap 


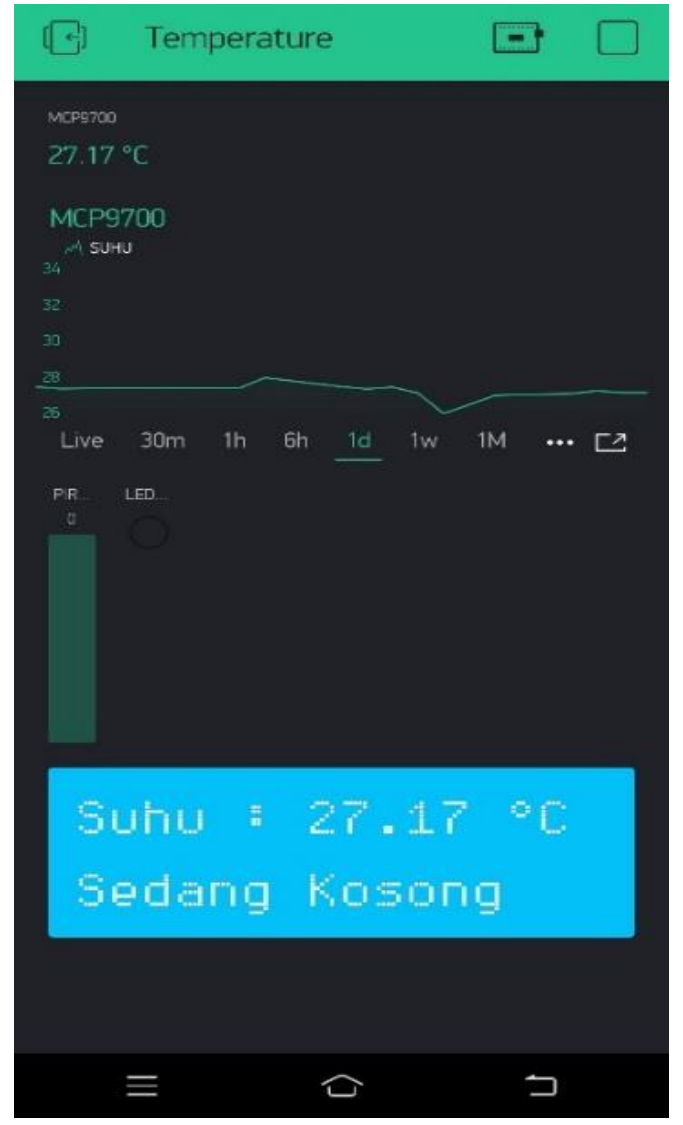

Gambar 6

Canvas perangkat pada Blynk

\section{PENUTUP}

Berdasarkan hasil penelitian yang telah dilakukan dapat disimpulkan bahwa pengujian perbedaan suhu antara Sensor MCP9700 dengan ThermoHigrometer HTC-1 adalah 0.31. Hasil pengukuran menujukkan bahwa suhu yang diukur perangkat tidak memiliki perbedaan besar dengan hasil pengukuran suhu perangkat lain.

$$
\text { Apabila suhu ruangan }
$$
melebihi 40 derajat celcius maka secara otomatis sistem akan mengirim peringatan melalui email bahwa suhu pada ruangan berada diluar ambang batas normal. 


\section{REFERENCES}

Annamaa, A. (2015). Introducing Thonny, a Python IDE for learning programming. In Proceedings of the 15th Koli Calling Conference on Computing Education Research - Koli Calling '15 (Vol. 19-22-Nov-, pp. 117-121). New York, New York, USA: ACM Press. https://doi.org/10.1145/2828959.2828969

De Paolis, L. T., De Luca, V., \& Paiano, R. (2018). Sensor data collection and analytics with thingsboard and spark streaming. EESMS 2018 - Environmental, Energy, and Structural Monitoring Systems, Proceedings, 1-6. https://doi.org/10.1109/EESMS.2018.8405822

Fan, X., Xie, Q., Li, X., Huang, H., Wang, J., Chen, S., ... Chen, J. (2017). Activity Recognition as a Service for Smart Home: Ambient Assisted Living Application via Sensing Home. In 2017 IEEE International Conference on AI \& Mobile Services (AIMS) (pp. 54-61). IEEE. https://doi.org/10.1109/AIMS.2017.29

Kamalakannan, M., \& Devadharshini, K. (2019). Controlling the Speed of Conveyor Belt using Python - Raspberry Pi 3B+. Oriental Journal of Computer Science and Technology, 12(2), 57-64. https://doi.org/10.13005/ojcst12.02.05

Kashyap, M., Sharma, V., \& Gupta, N. (2018). Taking MQTT and NodeMcu to IOT: Communication in Internet of Things. Procedia Computer Science, 132(Iccids), 16111618. https://doi.org/10.1016/j.procs.2018.05.126

Koo, D. D., Lee, J. J., Sebastiani, A., \& Kim, J. (2016). An Internet-of-Things (IoT) System Development and Implementation for Bathroom Safety Enhancement. Procedia Engineering, 145, 396-403. https://doi.org/10.1016/j.proeng.2016.04.004

Mao, X., Li, K., Zhang, Z., \& Liang, J. (2017). Design and implementation of a new smart home control system based on internet of things. In 2017 International Smart Cities Conference (ISC2) (pp. 1-5). IEEE. https://doi.org/10.1109/ISC2.2017.8090790

Media's, E., . S., \& Rif an, M. (2019). Internet of Things (IoT): BLYNK Framework for Smart Home. KnE Social Sciences, 3(12), 579. https://doi.org/10.18502/kss.v3i12.4128

Microchip Technology Incorporate. (2007). Low-Power Linear Active Thermistor ICs MCP9700/9700A MCP9701/9701A Datasheet.

Pareek, T. G., Padaki, R., Iyer, A., \& Priya, G. (2017). App Based Device Controlling System. International Journal of Advanced Research in Computer Science, 8(5), 2121-2125.

Park, E., Cho, Y., Han, J., \& Kwon, S. J. (2017). Comprehensive Approaches to User Acceptance of Internet of Things in a Smart Home Environment. IEEE Internet of Things Journal, 4(6), 2342-2350. https://doi.org/10.1109/JIOT.2017.2750765

Patel, K. K., Patel, S. M., Scholar, P. G., \& Iot, T. (2018). Introduction to IOT. International Journal of Engineering Science and Computing, 5(1), 41-44. https://doi.org/10.17148/IARJSET.2018.517

Perkasa, T. R., Widyantara, H., \& Susanto, P. (2014). Rancang Bangun Pendeteksi Gerak Menggunakan Metode Image Substraction Pada Single Board Computer (SBC). Journal of Control and Network Systems, 3(2), 90-97.

Syahidulhaq, H. A., Hafiddudin, H., \& Aulia, S. (2017). SISTEM KEAMANAN BERBASIS ALARM IP CAMERA DENGAN PASSIVE INFRARED RECEIVER (PIR) SENSOR DAN SMS GATEWAY. 
Monitoring Ruangan Berbasis Internet Of Things Menggunakan Thingsboard dan Blynk

Jurnal Elektro Dan Telekomunikasi Terapan, 3(2), 312-320. https://doi.org/10.25124/jett.v3i2.300

Vadillo, L., Martín-Ruiz, M. L., Pau, I., Conde, R., \& Valero, M. Á. (2017). A Smart Telecare System at Digital Home: Perceived Usefulness, Satisfaction, and Expectations for Healthcare Professionals. Journal of Sensors, 2017, 1-12. https://doi.org/10.1155/2017/8972350

Vaidya, V. D., \& Vishwakarma, P. (2018). A Comparative Analysis on Smart Home System to Control, Monitor and Secure Home, based on technologies like GSM, IOT, Bluetooth and PIC Microcontroller with ZigBee Modulation. In 2018 International Conference on Smart City and Emerging Technology (ICSCET) (pp. 1-4). IEEE. https://doi.org/10.1109/ICSCET.2018.8537381

Wagyana, A., Zulhelman, \& Rahmat. (2019). Development of Multi-Sensor Smart Power Outlet to Optimize Building Electrical Automation System. Journal of Physics: Conference Series, 1364(1), 012033. https://doi.org/10.1088/1742-6596/1364/1/012033

Wai Zhao, C., Jegatheesan, J., \& Chee Loon, S. (2015). Exploring IOT Application Using Raspberry Pi. International Journal of Computer Networks and Applications, 2(1), 27-34. Retrieved from http://www.digi.com

Xu, H., He, Y., Sun, X., He, J., \& Xu, Q. (2020). Prediction of thermal energy inside smart homes using IoT and classifier ensemble techniques. Computer Communications, 151, 581-589. https://doi.org/10.1016/j.comcom.2019.12.020

Zhu, Z. M., Xu, F. Q., \& Gao, X. (2020). Research on school intelligent classroom management system based on internet of things. Procedia Computer Science, 166, 144-149. https://doi.org/10.1016/j.procs.2020.02.037

Zlatanov, N. (2016). Arduino and Open Source Computer Hardware and Software. Journal of Water, Sanitation and Hygiene for Development, 10(11), 1-8. https://doi.org/10.13140/RG.2.1.1071.7849 